\title{
The harmful practice of indicating ancillary tests among non- medical professionals
}

Under the spurious argument of preventing unapparent health problems, for a long time now, children, their parents, and pediatricians have been continuously annoyed with requests for unnecessary tests in healthy children. Such tests requests come from different institutions working with children, especially kindergartens, schools, and sport clubs. In this setting, pediatricians are bashed with a load of requests for prescriptions of electroencephalograms, echocardiographies, electrocardiograms, audiometry exams, and several other tests. To make matters worse, these tests are not requested by skilled health care providers with experience in the field related to the requested tests but by non-medical professionals. Electroencephalograms have been requested by teachers and educational psychologists; electrocardiograms and echocardiographies, by physical education teachers, etc. Sometimes they claim these are institutional decisions. Of course, neither these non-medical professionals nor the institutions where they work bear the costs, which are paid by the patients, or take responsibility for the results. If a test shows an abnormal or complicated result, the person requesting the test leaves the responsibility for the problem aside and simply tells the child and his/ her family to "see a specialist" (not even offering to help).

Such tendency has no scientific grounds, is not beneficial for child health, and fails to prevent any health problem. It is important to know that, for a disease to be subjected to a screening process, a series of conditions have to be met in relation to the disease that is being studied and the methods to be used. Several scientific publications support this; and very few childhood diseases may be prevented or detected through screening methods. ${ }^{1-2}$ It is worth recalling that these are tests performed on healthy individuals, who should not be exposed to such discomfort, inconveniences or expenses caused by an irresponsible decision made by people or institutions dealing with children.

A previous editorial published in the Archivos Argentinos de Pediatría warned against this tendency. ${ }^{3}$ We are sure that both health authorities and the technical agencies of the Sociedad Argentina de Pediatria will share this point of view and make sure that the institutions behind such practices become aware of their uselessness and harm, and publish information on the rare conditions for which there is evidence that generalized (population) screening tests may be preventive (newborn screening, otoacoustic emissions [OAE], Adam's forward bend test, physical growth, unapparent developmental problems, and probably a few more). These tests are certainly requested by pediatricians and pediatric specialists, and remain under their responsibility, not by any other non-medical professional.

Horacio Lejarraga, M.D.

Honorary Professor of Universidad de Buenos Aires E-mail address: cursotesis07@gmail.com

http: / / dx.doi.org/10.5546/ aap.2019.eng.212

To cite: Lejarraga H. The harmful practice of indicating ancillary tests among non-medical professionals. Arch Argent Pediatr 2019;117(4):212.

\section{REFERENCES}

1. Frankenburg W, Camp BW. Pediatric Screening Tests. Springfield: Charles C. Thomas Co; 1985.

2. Lejarraga $\mathrm{H}$. La pesquisa de problemas de desarrollo. In: Lejarraga H (ed). Desarrollo del niño en contexto. Buenos Aires: Paidós; 2006.Págs.463-76.

3. Ceriani Cernadas JM. Las contradicciones e inequidades en la prevención en medicina. Arch Argent Pediatr. 2014; 112(3)202-3. 